\title{
RACHEL DE QUEIROZ E CECÍLIA MEIRELES EM LIVROS DIDÁTICOS DE LITERATURA SOB A PERSPECTIVA DA ANÁLISE CRÍTICA DO DISCURSO
}

\author{
RACHEL DE QUEIROZ AND CECÍLIA MEIRELES' REPRESENTATION IN \\ LITERATURE TEXTBOOKS: A CRITICAL DISCOURSE ANALYSIS
}

\author{
Alzenira Aquino de Oliveira ${ }^{1}$ \\ Anna Gabriella Cavalcante Mamede de Almeida ${ }^{2}$ \\ Estela Carielli de Castro ${ }^{3}$
}

Recebido em: 29/10/2020

Aprovado em: 20/11/2020

\begin{abstract}
RESUMO: Este artigo tem como objetivo analisar o discurso sobre Rachel de Queiroz e Cecília Meireles, pertencentes ao período literário moderno, para observar como elas são representadas nos livros didáticos de Ensino Médio. Para embasar a discussão, utilizamos as noções de discurso (FAIRCLOUGH, 2004, 2016) e contexto (VAN DIJK, 2009; FAIRCLOUGH, 2016), relacionando com a Teoria da Representação Social (VAN LEEUWEN, 2008). Assim, foram analisados 3 livros didáticos de Ensino Média a partir das categorias de functionalization e rough polítical allignment. Desse modo, a partir da análise, concluímos que Rachel de Queiroz é apresentada como uma figura ameaçadora e reduzida a sua obra O quinze, enquanto Cecília Meireles é a mulher considerada ideal, ligada ao feminino e ao sensível.
\end{abstract}

Palavras-chave: Análise Crítica do Discurso. Representação social. Modernismo Brasileiro.

ABSTRACT: The aim of this article is to analyze the discourse about Rachel de Queiroz e Cecília Meireles, brazilian modernist authors, in order to observe how they are represented in high school textbooks. To promote such a discussion, we present the notions of discourse (FAIRCLOUGH, 2004, 2016) and context (VAN DIJK, 2009; FAIRCLOUGH, 2016), connected to Social Representation Theory (VAN LEEUWEN, 2008). Thus, 3 high school textbooks were analyzed considering functionalization and rough political alignment categories. As result, we conclude that Rachel de Queiroz is reduced to her novel O quinze and represented as a threatening figure while Cecília Meireles is related to sensitivity, femininity and considered the ideal woman.

Keywords: Critical Discourse Analysis. Social Representation. Brazilian modernism.

\section{INTRODUÇÃO}

Segundo Maluf e Mott (1998), o início do século XX é de grande importância para a história, pois se constitui como um período de busca pelo progresso; período marcado por uma intensa urbanização e modernização, refletindo no papel social das mulheres. As instituições sociais reforçaram/estabeleceram que a função da mulher seria exercer o papel de mãe-esposa-dona de casa. Isso implica dizer que foi construído um imaginário de como a mulher deve ser/agir.

Essa redução da mulher ao espaço da casa, como detentora da honra da família e completamente submissa ao marido, dependendo, inclusive, da autorização prévia dele para poder trabalhar

\footnotetext{
1 Doutoranda em Linguística pela Universidade Federal de Sergipe (UFS).

2 Mestranda em Linguística pela Universidade Federal de Sergipe (UFS).

3 Mestranda em Linguística pela Universidade Federal de Pernambuco (UFPE).
} 
(apenas alguns trabalhos específicos eram permitidos, como as funções de secretária, professora, costureira etc.) nos remete ao discurso de Virginia Woolf $f^{4}$ de se ter um espaço e dinheiro próprios para poder escrever ficção, o que nos leva a tão poucas mulheres escritoras na história "oficial" da literatura. Além das dificuldades econômicas e políticas, há outro problema: aquelas que conseguiam escrever, em muitos casos, se perdiam na história, sem sequer serem lembradas (JAFFE, 2014). Assim, a divisão de papéis entre homens e mulheres de maneira desigual, trouxe mais poder aos homens e invisibilizou as mulheres, que foram ligadas a uma imagem de fragilidade. Assuntos externos ao domínio da casa se tornaram masculinos e os temas que envolviam a casa, tornam-se dever da mulher. Isso implica nas relações entre o público e o privado.

A partir desse breve panorama, no qual há uma estrutura patriarcal que afeta o domínio literário, põe os homens em situação de privilégio, fazendo com que poucas mulheres apareçam nos livros de história da literatura brasileira, seja pela falta de um teto próprio, seja pelo não reconhecimento, surgindo grandes nomes apenas a partir do modernismo, gostaríamos de refletir como as escritoras da geração de 30, são representadas nos livros didáticos. Esse interesse surge pela influência que o domínio educacional possui, capaz de perpetuar discursos que mantém o status quo ou que transformam a realidade. Dessa maneira, foram escolhidas as autoras Rachel de Queiroz e Cecília Meireles por ambas fazerem parte do modernismo da geração de 30, e serem duas das poucas autoras presentes nos livros didáticos. Assim, além de ser possível analisar como cada autora é representada, é possível observar diferenças e semelhanças entre esses discursos, traçando um comparativo.

É importante levar em consideração que os livros didáticos fazem parte do discurso educacional e possuem influência, pois, além de se constituírem como um texto-base para o professor, constituem leitura obrigatória para os alunos (VAN DIJK, 2009). No entanto, o professor tem um papel fundamental nesse processo, já que ele é o responsável por complementar as informações apresentadas, questioná-las, debatê-las, porém, como bem afirma Van Dijk (2009, p.106, tradução nossa):

Qualquer intenção por parte de, por exemplo, os professores, de se oporem a essa versão, implica ter amplos conhecimentos e acesso a outras fontes de informação, além da liberdade (geralmente restringida) de afastar-se dos programas e das tradições estabelecidas".

Destacamos esse aspecto, porque não desconsideramos o papel do professor nesse processo, contudo, a análise deste trabalho trata especificamente do discurso presente no livro didático, entendendo-o como um discurso influente no processo educacional.

Pautamo-nos sob a perspectiva do discurso como representação social e agente transformador (FAIRCLOUGH, 2016, 2003), sendo o discurso o objeto de análise deste trabalho, e da noção de contexto (FAIRCLOUGH, 2016; VAN DIJK, 2009), pois, ele é relevante para compreendermos a história das mulheres na literatura e na sociedade, e por atuar enquanto regulador do discurso. Dessa forma, o objetivo deste trabalho é analisar como as escritoras Cecília Meireles e Rachel de Queiroz são representadas nos livros didáticos de história da literatura brasileira do Ensino Médio no período do modernismo brasileiro. Dessa maneira, o corpus se constitui de três livros didáticos do Ensino Médio: Lingua, literatura \& produção de texto: volume 3 (2012), Editora Scipione; Português contemporâneo: diálogo, reflexão e uso. Volume 3 (2016), Editora Saraiva, e Veredas da palavra: volume 3, Editora Ática. Para a análise, utilizamos a Teoria de Representação de Atores Sociais (VAN LEEUWEN, 2008), expandida por Reisigl e Wodak (2001), por se tratar de uma perspectiva socio-semântica que entende a representação de atores/grupos sociais como uma forma de produzir sentido sobre eles, da qual optamos por trabalhar com as seguintes categorias: functionalization e rough political allignment.

4 Discurso proferido em uma série de palestras dadas pela autora na Universidade de Cambridge, em 1928.

https://periodicos.unifap.br/index.php/letras

Macapá, v. 10, n. 1, $1^{\circ}$ sem., 2020 


\section{DISCURSO E CONTEXTO NA ANÁLISE CRÍTICA DE DIS- CURSO}

A Análise Crítica de Discurso (ACD) é uma teoria multidisciplinar e heterogênea, que considera os aspectos culturais e históricos de uma sociedade para compreensão do discurso. Além disso, é crítica porque busca um engajamento social no sentido de procurar contribuir com mudanças para as minorias. Por isso, é comum que os trabalhos se voltem para questões raciais, de gênero, LGBTQI+, entre outros grupos minoritários. Essa preocupação surge, pois, segundo Van Dijk (2009, p.19), o objeto da ACD é a reprodução discursiva do abuso de poder e da desigualdade social, dessa forma, as dominações que geram abuso de poder são o foco da ACD e, consequentemente, isso ocorre porque o autor enxerga "[...] o poder social em termos de controle, isto é, de controle de um grupo sobre outros grupos e seus membros." (VAN DIJK, 2009, p.30, tradução nossa).

Ressaltamos algumas diferenças nos estudos de Fairclough e Van Dijk. Fairclough (2016) não nega a cognição no processo interativo e social, mas Van Dijk (2009) adiciona de fato essa interface cognitiva para a ACD como extremamente relevante e desenvolve a teoria dos modelos mentais totalmente pautada na cognição, além do social e do interacional. Para Fairclough (2016), a ACD também está atrelada à mudança social e desenvolve um quadro teórico com o objetivo de alcançar essa mudança. Para o autor, a linguagem é uma prática social. Isso significa dizer que estas são práticas compartilhadas por um senso comum e produzidas pelas pessoas. A linguagem, então, não é apenas constituinte da sociedade, mas tem o poder de transformá-la.

Sendo assim, o discurso é uma forma de ação e, consequentemente, uma forma de agir sobre o mundo: o discurso constrói, através de um processo interacional, identidades, sujeitos sociais, relações sociais, objetos. Lembrando que, embora a prática social e a prática discursiva sejam conceitos diferentes, em muitos casos, a prática discursiva é constituinte da prática social, principalmente porque das práticas sociais ecoam discursos. Portanto, "O discurso é uma prática, não apenas de representação do mundo, mas de significação do mundo, constituindo e construindo o mundo em significado" (FAIRCLOUGH, 2016, p. 95).

A noção de contexto vem sendo discutida, além da Linguística, em outras áreas, como no campo das Ciências Sociais. De acordo com Van Dijk (2009), se em alguns campos de estudos o contexto é visto de forma mais restrita, sendo entendido como situacional e objetivo, para a ACD, o contexto é algo mais amplo, englobando não apenas uma situação objetiva, mas também a subjetividade; o contexto só aparece a partir da intervenção do leitor/faltante/produtor. O contexto, dessa forma, é o que é posto como relevante. $\mathrm{Na}$ definição do autor, os contextos aparecem como "[...] definições dos aspectos relevantes da situação comunicativa feitas pelos próprios interventores" (VAN DIJK, 2009, p.38, tradução nossa). Portanto, o contexto é dinâmico, pode ser atualizado, é situado histórico, sócio e culturalmente, ocorre na interação entre autor/leitor ou entre falantes e também possui uma face cognitiva, pois, para o autor, há o microcontexto e o macrocontexto, sendo o micro referente ao contexto mais imediato, algo exposto em uma situação comunicativa, e o macro um contexto mais amplo capaz de ser acessado através da memória.

Fairclough (2016, p.115) traz o contexto como algo que está fora do texto, o que precede (ou segue) em um texto: "[...] os intérpretes chegam a interpretação da totalidade da prática social da qual o discurso faz parte, e tais interpretações conduzem a predições sobre os sentidos dos textos que novamente reduzem a ambivalência pela exclusão de outros sentidos". A perspectiva de Fairclough (2016) se assemelha a de Van Dijk (2009), pois ambos apontam o contexto como regulador do discurso e dependente da subjetividade, já que algo será posto como relevante e isso implica dizer que outros assuntos serão excluídos. Assim, controlar o contexto é ter poder, pois também configura o controle das informações colocadas na produção discursiva.

É por ser tão influente para o discurso que o conceito de contexto se faz importante para este trabalho, já que, nos livros didáticos, há um microcontexto que situa o leitor em relação as 
autoras aqui trabalhadas apresentadas a partir da vida e obra delas; e um contexto mais amplo, construído no processo interacional e cognitivo (através da memória) na relação autor-texto-leitor. Pretendemos, dessa forma, focar no microcontexto, já que entendemos que é ele quem vai trazer apontamentos do que é posto como relevante ou não acerca de Rachel de Queiroz e Cecília Meireles, nos auxiliando a compreender como essas autoras são representadas.

\section{A TEORIA DA REPRESENTAÇÃO DE ATORES SOCIAIS: DIÁLO- GOS COM A ACD}

Fairclough (2003), além de trazer a noção de discurso como ação, defende a relação entre discurso e representação, já que o discurso é uma forma de representar e produzir significado sobre o mundo social. Tal perspectiva se alinha com a teoria de Van Leeuwen (2008, p. 4, tradução nossa) sobre a forma como representamos o mundo através do uso da linguagem: “[...] textos deveriam ser estudados como representações assim como interações". Por isso, entendemos que textos vão além da capacidade comunicativa entre atores/grupos sociais. O autor estabelece uma diferença entre práticas sociais e representações de práticas sociais. A primeira é interpretada como a forma de um ator/grupo social age perante o mundo. A segunda é a forma como nós produzimos significado sobre a prática social, ou seja, como a representamos. Apesar de serem interdependentes, ambos os conceitos são distintos, pois, para Van Leeuwen (2008) representações sociais são realizadas linguisticamente através do discurso. Ou, nas palavras do autor, "discursos são cognições sociais, formas sociais específicas de entender práticas sociais [...] (VAN LEEUWEN, 2008, p.6, tradução nossa)".

A discussão de Van Leeuwen (2008) se estende para além da representação de práticas sociais. Dentro das realizações linguísticas observamos a representação de atores/grupos sociais no discurso. Para isso, o autor desenvolveu a Teoria de Representação dos Atores Sociais, pois estudar a representação nos permite compreender como significados são construídos socialmente. Assim, utilizar a Teoria de Representação dos Atores sociais nos auxilia a observar como percepções sociais estão/são imbricadas no uso linguístico. Por isso, observar como Cecília Meireles e Rachel de Queiroz são representadas nos livros didáticos do Ensino Médio nos permite compreender quais são os sentidos construídos sobre as autoras.

Van Leeuwen (2008) apresenta diversas categorias socio-semânticas que perpassam pela realização linguística. O foco do autor é identificar como os sentidos são construídos através da representação de atores/grupos sociais em textos. Como as formas de representar variam de acordo com o local em que estamos inseridos, as categorias aparecem de acordo com as formas como atores/grupos sociais representam o mundo social. Sendo assim, a Teoria de Representação de Atores Sociais foi expandida por Reisigl e Wodak $(2001)^{5}$, que adotaram algumas categorias apresentadas por Van Leeuwen (2008) e outras foram expandidas/criadas. Por existirem diversas formas de representar grupos/atores sociais, apenas as categorias que apareceram nos nossos dados serão apresentadas a seguir.

\subsection{Categorias de análise: functionalization e rough political allign- ment}

A análise será realizada a partir dos parâmetros sobre a representação dos atores sociais propostos por Van Leeuwen (2008) e expandida por Reisigl e Wodak (2001). As categorias de repre-

\footnotetext{
$5 \mathrm{O}$ ano de publicação apresenta uma contradição entre as obras. Isso acontece porque A teoria de Representação dos Atores Sociais foi publicada em um artigo escrito por Van Leeuwen em 1996, mas a sua publicação em livro (Discourse and practice: New tools for Critical Discourse Analysis) ocorreu apenas em 2008.
}

https://periodicos.unifap.br/index.php/letras

Macapá, v. 10, n. 1, $1^{\circ}$ sem., 2020 
sentação apresentadas aqui são: functionalization, elaborada por Van Leeuwen (2008) e rough polítical alignment, elaborada por Reisigl e Wodak (2001). Tais categorias não aparecem isoladas, são realizadas em um microcontexto que tem, como assunto principal, a vida e obra das autoras modernistas.

A categoria functionalization é relacionada à função exercida por atores/grupos sociais no mundo. Van Leeuwen (2008, p. 42) demonstra que a functionalization "ocorre quando atores sociais são referenciados em relação a uma atividade, associados a algo que exercem, por exemplo, uma ocupação ou papel." Ou seja, se atores/grupos sociais são realizados linguisticamente pela função social que exercem, a produção de sentido depende do contexto no qual estão inseridos. Por isso, para analisar a representação de atores/grupos sociais é necessário considerar o contexto. No caso desta pesquisa, se considerarmos o contexto sócio-histórico em que mulheres escritoras estão/são inseridas, ressaltar tais papéis sociais é um aspecto positivo na produção de sentido. Ou, nas palavras de Van Leeuwen, (2008, p. 44) a forma de representar atores/ grupos sociais através de suas funções exercidas no mundo são a "chave para estabelecer uma relação" no mundo ocidental.

Já a representação por rough political alignment é uma subcategoria de politicisation (REISIGL; WODAK, 2001) e acontece quando atores/grupos sociais são realizados linguisticamente por termos que demonstram seu alinhamento político. Tal subcategoria se configura como uma forma de polarização ao representar linguisticamente atores/grupos sociais por termos que apresentam suas perspectivas políticas. Assim, a depender do contexto estabelecido, a produção de significado pode conter aspectos positivos ou negativos referentes a determinados posicionamentos políticos.

\section{PROCEDIMENTOS METOdológicos}

Ao analista crítico do discurso compete utilizar, entre outras, a metodologia aplicada qualitativa sob a perspectiva interpretivista, pois quem delimitará o método será a escolha teórica, o objeto e os objetivos da pesquisa, em busca de revelar situações de injustiça social como forma de diminuir desigualdades entre grupos/atores sociais. Os estudos qualitativos focam em observar como os contextos sociais nos quais os grupos/atores sociais estão inseridos têm papel fundamental na construção de significado. Por isso, o foco da pesquisa qualitativa é "elucidar e conhecer os complexos e processos de constituição da subjetividade” (HOLANDA, 2006).

Por não possuir um modelo fixo a ser seguido, a ACD depende da observação dos dados para que os elementos linguístico-discursivos apareçam e sejam destacados durante a análise. Por isso, Magalhães, Martins e Resende (2017) sugerem algumas etapas a serem seguidas durante a pesquisa, são elas:

Quadro 1 - Possíveis etapas de uma pesquisa em ACD

\begin{tabular}{|l|l|}
\hline $1^{\circ}$ Passo & Selecionar problema/situação social com que se pretende trabalhar \\
\hline $2^{\circ}$ passo & Definir e recolher os textos para o corpus da investigação \\
\hline $3^{\circ}$ passo & $\begin{array}{l}\text { Identificar e selecionar aspectos gramaticais e discursivos dos textos do corpus entre os mais relevantes } \\
\text { para os propósitos da pesquisa }\end{array}$ \\
\hline $4^{\circ}$ passo & Proceder ao exame dos textos \\
\hline $5^{\circ}$ passo & Relacionar textos e contextos discursivo e social por meio da pesquisa etnográfica \\
\hline
\end{tabular}

Fonte: Magalhães, Martins e Resende (2017, p. 58).

Embora os autores voltem-se para a metodologia etnográfica, entendemos que podemos seguir tais orientações de forma que a análise de dados documental (RAMALHO; RESENDE, 2011) seja elaborada para compreender como as autoras modernistas Rachel de Queiroz e Cecília Meireles são realizadas linguisticamente em livros didáticos do Ensino Médio. Portanto, conforme a sugestão dos autores, para este artigo, realizamos as seguintes etapas:

i) O problema social selecionado foi a representação das autoras Rachel de Queiroz e Cecília Meireles em livros didáticos do Ensino Médio, visto que a educação pode ser uma forma de perpetuar

https://periodicos.unifap.br/index.php/letras

Macapá, v. 10, n. 1, $1^{\circ}$ sem., 2020 
o status quo ou transformação de realidade. O corpus é constituído a partir dos textos sobre as autoras Rachel de Queiroz e Cecília Meireles;

ii) Selecionamos os livros didáticos a serem trabalhados: Lingua, literatura \& produção de texto: volume 3 (2012), Editora Scipione, Português contemporâneo: diálogo, reflexão e uso. Volume 3 (2016), Editora Saraiva, e Veredas da palavra: volume 3 ,Editora Ática, que para fins de análise serão denominados respectivamente como Livro A; Livro B; Livro C. A escolha desses livros se pauta em buscar uma diversidade de editoras, apresentando diferentes pontos de vista. iii) Após a leitura do aporte teórico, observamos os trechos selecionados dos livros, e as categorias linguístico-discursivas (VAN LEEUWEN, 2008) (REISIGL; WODAK, 2001) que se destacaram foram as seguintes: functionalization e rough political alignment.

iv) Depois que as categorias e subcategorias foram encontradas, uma análise mais aprofundada do microcontexto em relação à vida e obra dessas autoras foi elaborada a fim de compreender como as autoras modernistas são representadas nos livros didáticos.

v) Por fim, relacionamos o contexto à forma como as escritoras modernistas foram representadas no texto. A análise virá na seção a seguir.

\section{ANALISANDO OS LIVROS DIDÁTICOS}

\subsection{Rachel de Queiroz}

Nos livros didáticos, o que foi observado é que a forma como a autora é representada relaciona-se com a função social (VAN LEEUWEN, 2008), na perspectiva de trabalho que ela exerce. No livro A, por exemplo, a escritora é relacionada à profissão de professora e jornalista. No entanto, apesar de os autores mencionarem que a escritora produziu romances, crônicas e peças teatrais, estas são informações secundárias se relacionarmos ao destaque que dão a obra O quinz̧e. Além disso, ao não ativarem Rachel de Queiroz como escritora, romancista, autora e/ou dramaturga o valor social atribuído à modernista se torna limitado, pois suas funções sociais no movimento modernista não são enfatizadas.

Se considerarmos o microcontexto que aborda Rachel de Queiroz e sua obra, temos primeiramente uma apresentação das principais obras da autora. Logo após, os autores falam especificamente da obra $O$ quinze. Finalmente, os autores apontam que pela escrita de Rachel ser objetiva, os críticos, à época, acreditavam se tratar de uma obra de autoria masculina. Os autores utilizam essas informações para demonstrar que a escritora rompeu padrões de pensamento para a época, discorrendo que mulheres podem abordar temas sociais em suas produções. Tal rompimento não é aprofundado pelos autores e, apesar de ter sido apresentado como principal característica da autora, a temática abordada para uma breve análise de $O$ quinz̧e aponta para a investigação do feminino. $\mathrm{O}$ texto aprofunda a questão do feminino ao demonstrar que Rachel de Queiroz se volta para em outras obras, como no romance Memorial de Maria Moura, e tal abordagem demonstra que a temática da escritora rompe padrões por construir uma personagem forte e que "reinventa o mito da mulher guerreira" (HERNANDES; MARTIN, 2016, p. 193).

Outra informação apontada é que ela foi a primeira mulher a entrar para a Academia Brasileira de Letras (ABL), é pertinente observar que apenas o livro A informa a data desse acontecimento - 1977. Não há informações de que a ABL foi fundada no ano de 1897, e isso significa dizer que apenas 80 anos após a fundação da instituição é que temos uma mulher eleita para fazer parte dela. Não há maiores reflexões sobre as causas desse fato, nem sobre as repercussões disso para a própria Literatura. Ao mesmo tempo em que se inclui essa informação, a organização do texto não dá relevância para esse aspecto.

Já no livro B, observamos um box separado para a biografia da escritora. O início do texto apresenta a informação do parentesco de Rachel de Queiroz com José de Alencar. Trata-se, então, da questão de que, nessa biografia, a forma como a autora é identificada (VAN LEEUWEN, 2008)

https://periodicos.unifap.br/index.php/letras

Macapá, v. 10, n. 1, $1^{\circ}$ sem., 2020 
acaba desfocando a apresentação de Rachel de Queiroz, por ela mesma, como aspecto principal. Por outro lado, os autores do livro fazem menção a Rachel de Queiroz destacando sua função social (VAN LEEUWEN, 2008) no movimento modernista, sendo colocada como "escritora" e "romancista" no texto, informações que diferem do livro A, que aponta a autora como "professora" e "jornalista". Representar a autora como "escritora" e "romancista" é necessário, pois demarca a função social dela no movimento modernista. Além disso, ela é associada à dramaturgia e crônica jornalística, informações que, ao não serem colocadas como função social ("dramaturga", "cronista") da escritora, não demonstram a relevância social de Rachel de Queiroz no movimento modernista. Tais informações se assemelham ao livro A, que também não representa a escritora como "dramaturga" ou "cronista".

Mais adiante no texto as informações biográficas demonstram a ligação da escritora com a seca e o sertão, ao colocarem a escritora Rachel "manteve-se ligada à sua fazenda" (CEREJA; DAS VIANNA; DAMIEN, 2016, p.102) que se localizava no estado do Ceará. Os autores colocam Rachel como agente (VAN LEEUWEN, 2008) ao demonstrar que era "admiradora" das ideias de Trotsky e depois utilizam a passivação (VAN LEEUWEN, 2008) para demonstrar que foi "presa" por acusação de comunismo. No entanto, não apontam os agentes que acusaram e prenderam a escritora, assim, não são apontados culpados. Existe uma relação de causa e consequência quando informam que a autora foi presa, pois, ao informar a prisão dela, colocam que foi por causa do alinhamento ideológico com as ideias de Trotsky. O texto, no entanto, não menciona que o Brasil estava em uma ditadura política ideológica que defendia e exercia ideais fascistas. Ao colocá-la como comunista, o termo se refere ao alinhamento político (REISIGL; WODAK, 2001) da autora, mas não se tem um aprofundamento dessa perspectiva e o porquê de a autora manter tal posicionamento.

No subtópico do livro B que se refere à obra de Rachel de Queiroz como "prosa enxuta, visão crítica das relações sociais e análise psicológica das personagens" (CEREJA, W.; DIAS VIANNA, C.; DAMIEN, C. 2016, p. 102), o texto demonstra uma visão objetiva e política sobre os temas abordados pela autora. A discussão da obra de Rachel de Queiroz é ampla, não se reduz a sua principal obra $O$ quinže; pelo contrário, apresenta características marcantes das produções escritas da autora, relacionando-as às primeiras características apresentadas, exemplificando a parte de "análise psicológica" dos personagens, e, em relação a questões políticas, é mencionada a "defesa dos ideais socialistas", informação que concorda com o que foi apresentado no box biográfico da autora.

Além disso, o livro categoriza as correntes ideológicas que inspiraram a obra Caminho de Pedras como "comunistas" e "integralistas". Isso demonstra um distanciamento do texto em relação à parte "integralista", pois, ao colocar que o movimento ideológico foi "inspirado" no fascismo, não aponta que a ideologia integralista era fascista, ou seja, era uma ramificação do movimento fascista que se enraizou no Brasil. Assim, ao mencionar que o romance é "político" e defensor dos ideais socialistas, o texto parece demonstrar que existe uma polarização entre os movimentos ideológicos. No entanto, sabemos que movimentos fascistas são baseados em ideais de exclusão de certos grupos sociais, enquanto os movimentos socialistas buscavam transpor desigualdades sociais a fim de promover uma sociedade mais igualitária. Tal aprofundamento político das obras de Rachel de Queiroz não é encontrado no livro A, que volta sua análise para o tema da seca e detalha a temática da investigação feminina nas produções da autora. Por outro lado, se aproxima dos livros A e C quando menciona que a escritora foi a primeira mulher a assumir uma cadeira na ABL. Se distancia, no entanto, quando não menciona o ano de tal feito, como ocorre no livro A ou não demonstra que Rachel de Queiroz “quebrou uma tradição”, como é colocado no livro C.

No livro C, encontramos um box semelhante ao livro B que trata da biografia da autora. Apesar de não ser colocada ativamente como escritora, é mencionado que sua vida profissional iniciou através de publicações de crônicas em jornais. Ou seja, a sua função social (VAN LEEUWEN, 2008) como escritora/romancista não está explicitamente colocada no texto, como acontece no livro A. Além disso, o box biográfico se resume a mencionar a dedicação de Rachel de Queiroz 
a crônicas, peças de teatro e romances sem mencionar que são funções sociais efetivas da escritora no movimento modernista. Tal leitura permite que Rachel de Queiroz não desempenhe a função social como agente romancista, escritora, cronista e dramaturga no movimento modernista.

Mais adiante é associada ao Partido Comunista Brasileiro, e o texto menciona que ela "militou" para tal partido e, por consequência disso, foi presa. A informação da prisão da escritora também é encontrada no livro B. O livro $\mathrm{C}$ trata essas questões de forma semelhante ao livro $\mathrm{B}$, porém relaciona o encarceramento à militância de Rachel de Queiroz a favor do Partido Comunista Brasileiro. O texto, no entanto, não aponta explicitamente a responsabilidade da "polícia de Getúlio" por não mencionar que, em 1937, acontecia a ditadura do Estado Novo. A falta de informação pode produzir o significado de que a escritora cearense estava agindo contra a lei, quando, de fato, estaria se manifestando a favor da democracia e indo de encontro ao autoritarismo do Estado Novo, com ideais fascistas. Além disso, o texto demonstra que Rachel de Queiroz "renegou seu passado esquerdista" e apoiou o golpe militar de 1964. Tais informações trazem uma produção de sentido de oposição entre os ideais da escritora e propõe que o passado de Rachel de Queiroz era "esquerdista" pode produzir um sentido negativo, quase pejorativo aos ideais políticos da romancista, pois menciona o alinhamento político (REISIGL; WODAK, 2001) dela. É interessante perceber que existe um desequilíbrio entre as perspectivas ideológicas tratadas no texto. Não é mencionado, por exemplo, que o Golpe Militar de 64 instaurou uma ditadura no país.

Nas partes referentes à obra de Rachel de Queiroz são mencionados o regionalismo, aspectos sociais e análise psicológica. Nesse momento, existe um único destaque para sua função social de "romancista" como o subtópico coloca. Ao utilizar esse termo, o livro C se aproxima do livro B, que também representa a escritora como romancista. O primeiro enfoque do texto volta-se para as perspectivas sociais das produções da escritora. Tais informações conduzem a leitura para mencionar que a literatura produzida pela romancista é "engajada e esquerdizante". O termo "esquerdizante" é problemático, pois produz a ideia de que a autora traz uma obra capaz de "converter" seus leitores para a esquerda. Além disso, também se torna quase pejorativo, como o termo "esquerdista" mencionado anteriormente, visto que, a depender da interpretação/condução das aulas, tal perspectiva pode ser vista como negativa. As características mencionadas são referentes à obra Caminho de Pedras, que é mencionada como "romance mais social, mais político". O sentido produzido compõe uma relação de significado direta com seu ano de publicação, 1937, o início da ditadura instaurada por Vargas.

Além disso, o livro C se assemelha ao livro A e B ao mencionar que Rachel de Queiroz foi a primeira mulher a assumir uma cadeira na ABL. Apesar de não mencionar o ano em que tal feito foi realizado, o destaque aparece quando o texto demonstra que a escritora "rompeu uma tradição".

No geral, o livro B é o que mais afirma as funções sociais de Rachel de Queiroz ao representála como escritora, romancista e autora. Já o livro A, representa-a como professora e jornalista, funções sociais que não apresentam a relevância social da escritora no movimento modernista. $O$ livro C se assemelha ao livro B quando representa a escritora como "romancista". No entanto, essa é a única função social relacionada ao movimento modernista apontada para a autora.

Em todos os livros, os temas relacionados à análise psicológica e ao tema da seca são abordados. O livro A relaciona ambas as temáticas. Já o livro B dá destaque aos aspectos sociais e ideológicos da obra de Rachel de Queiroz e se aproxima do livro C, que também dá maior foco aos temas mencionados.

\subsection{Cecília Meireles}

O livro A inicia a apresentação de Cecília Meireles abordando os papéis sociais exercidos pela escritora. Ao demonstrar que ela é "contista, cronista, tradutora e poetisa" (HERNANDES; MARTIN, 2016, p.179), o significado produzido gera impacto pelas quatro funções exercidas por Cecília Meireles no movimento modernista, tal percepção gera um impacto na leitura do texto, pois 
valoriza a produção intelectual da autora. Aqui, a autora é caracterizada por temáticas e características estéticas de suas produções escritas, ou seja, a "instabilidade da vida e a fragilidade do ser" (HERNANDES; MARTIN, 2016, p.179), como é apontado no livro A. Ainda, a estética de Cecília Meireles é relacionada à "musicalidade" e "aparente espontaneidade", características abstratas que se relacionam diretamente com a temática apresentada pelo texto como "simultaneamente incisiva e delicada" (HERNANDES; MARTIN, 2016, p.179), tais características se complementam e caracterizam a obra da autora.

Além disso, temos a autora como pessoa que "anuncia" a sua obra, ao colocá-la como agente principal da ação social, o texto torna-a responsável pelas temáticas apresentadas na sua obra. Interessante observar que o texto não aborda a característica "incisiva" da autora. Visto que é um adjetivo voltado para uma ação relacionada ao corte, no texto, é utilizado como um sentido relacionado a algo que seria intenso e rápido, provavelmente podendo ser relacionado ao poema Romanceiro da inconfidência, pois a temática é relacionada a "busca obstinada por ouro, que gera disputas, prisões e até mesmo a morte" (HERNANDES; MARTIN, 2016, p.179). Algo que pareceria o oposto de como a obra da escritora é retratada, como algo delicado e frágil. Ainda é interessante ressaltar como, nos parágrafos introdutórios, a obra de Cecília é relacionada à sensibilidade e, no entanto, o poema escolhido para representar a produção da autora é relacionado a temas políticos e questões sociais.

Após a apresentação da obra de Cecília Meireles, temos uma pequena biografia. O texto ainda acrescenta que além das funções sociais exercidas pela autora de "contista, cronista, tradutora e poetisa", papéis sociais que se aproximam dos que são apresentados no livro B. Cecília Meireles também foi professora, informação que, pela localização no texto, parece ter menos importância que suas quatro funções mencionadas no início de sua apresentação. Tal contextualização resulta em uma diminuição da função exercida como professora pela autora, como uma informação que pudesse ser descartada. Isso resulta em uma desvalorização do papel social de sua formação formal e função exercida por Cecília em escolas do Rio de Janeiro, como o texto menciona. Ainda na biografia, os temas mencionados são "temas históricos" e "educacionais", percepções que não são abordadas no início do texto e, por consequência, podem passar despercebidas. Além disso, ao tratar a obra de Cecília como sentimental e delicada nos parágrafos iniciais, o texto demonstra não a relacionar a perspectivas políticas e sociais como é mencionado em sua biografia.

Já no livro B a biografia de Cecília é observada a função social (VAN LEEUWEN, 2008) de poetisa no final do box biográfico, parte do texto que contém informações sobre a vida da escritora. A autora, no entanto, é mencionada primeiramente como professora e depois é relacionada à sua produção escrita e ao vínculo com jornais através da publicação de crônicas e artigos referentes à educação. Em nenhum momento é colocada como cronista ou jornalista no box biográfico. Ao ser representada como "uma das principais vozes", acontece uma impersonalização (VAN LEEUWEN, 2008) através da representação metonímica da parte pelo todo, ou seja, a autora aqui não é ativada, é representada no texto metaforicamente por sua voz. É interessante observar que a biografia de Cecília Meireles se refere a sua vida profissional e informações pessoais são mencionadas apenas em relação aos seus pais e avós.

Em relação a sua obra, no livro B Cecília Meireles é representada de forma diferente de como foi apresentada no box biográfico. Nesta parte do texto, a escritora é representada como "poetisa", "cronista" e "contista", as funções sociais (VAN LEEUWEN, 2008) exercidas por ela no movimento modernista. Além disso, é representada como "intelectual" e "educadora". O segundo termo demonstra uma função social que é ainda mais aprofundada e romantizada que a de professora, pois, ao representarmos alguém que educa, a produção de significado se constitui como alguém com vocação, paciência, amor, dedicação, enquanto a expressão linguística professor pode remeterse mais a profissão e formação. Além disso, ambas as funções representadas no texto estão relacionadas ao "combate ao autoritarismo do Estado Novo". Tal associação repercute o porquê de ela se opor à ditadura da era Vargas. Também observamos que tal informação não veio no box biográfico e sim na parte sobre a obra dela. 
As produções literárias da escritora são relacionadas ao movimento neossimbolista. É interessante observar que o texto apresenta contrapontos sobre a escritora ao colocá-la como "essencialmente uma poetisa moderna" mas que está relacionada à "tradição ibérica da poesia" e como ela "cultivou o verso livre", mas que possuía "amplo domínio das formas poéticas convencionais (CEREJA; DAS VIANNA, DAMIEN, 2016, p.183)”. Afinal, qual a relação entre essas informações? Por que a escritora é apresentada com relações de oposição?

Por fim, no livro C, encontramos, primeiramente, um box com algumas informações sobre a vida de Cecília Meireles, relacionando-a ao magistério. O texto, no entanto, não aponta sua função social (VAN LEEUWEN, 2008) exercida como professora. As informações encontradas no box não são exclusivamente biográficas, voltam-se para uma introdução sobre as produções escritas da autora. O estilo e a temática são mencionados e, logo abaixo, existe um pequeno aprofundamento sobre a obra da poetisa, no entanto, sua principal produção, Romanceiro da Inconfidência, não é mencionada. A falta dessa informação pode fazer com que o leitor entenda que obra da escritora é exclusivamente relacionada a efemeridade da vida e que não apresenta percepções sociais. Ressaltese que apesar de apresentar um trecho de uma entrevista de Cecília Meireles, o texto não apresenta outras obras. A única produção apresentada nesta seção é seu livro de estreia, Espectros. Além disso, não são mencionadas outras funções sociais (VAN LEEUWEN, 2008) da autora, como cronista ou contista, como mencionado nos livros A e B.

De forma geral, a forma como a Cecília Meireles é representada nos livros A e B são semelhantes, pois ambos dão a devida importância à escritora no movimento modernista ao demarcarem seu papel social como "contista", "cronista", "poetisa" e "tradutora" (livro A) e "poetisa", "cronista", "contista" (livro B). Além disso, mencionam a autora como "professora" em ambos os livros e "educadora" e "intelectual" no livro B. Já no livro C não temos tal função demarcada.

Em todos os livros a temática da sensibilidade, efemeridade e derivados é abordada. Apesar de $O$ romanceiro da inconfidência tratar, também, de assuntos sociais, o tema é desprestigiado em relação a questões efêmeras apresentadas pela escritora em suas produções literárias.

\subsection{Comparação sobre a forma como Cecília Meireles e Rachel de Queiroz são representadas nos livros didáticos}

O livro A, ao colocar as funções sociais de Cecília Meireles logo de início, produz significados a partir da importância exercida pela autora no movimento modernista. Enquanto Rachel de Queiroz é apresentada através dos nomes de suas obras. Assim, a produção de significado dá destaque a Cecília Meireles, pois ela quem exerce as funções sociais de "contista, cronista, tradutora e poetisa" na escola literária. A temática e a estética de suas produções são abordadas antes de sua principal obra seja introduzida. Já Rachel de Queiroz tem sua temática abordada depois de serem apresentadas as suas produções literárias. Apesar de o poema Romanceiro da Inconfidência tratar de assuntos políticos, tema que, assim como nas produções literárias de Rachel de Queiroz é abordado por Cecília Meireles, tal posicionamento não é abordado pelo texto. Enquanto O quinž, apesar de demonstrar questões sociais mais amplas e de envolver um romance, é demonstrado através de uma perspectiva mais crítica e polêmica.

No que tange às biografias das autoras, observamos que o enfoque dado a Cecília Meireles é maior, pois, ao dar destaque para seu local de formação como professora e suas contribuições em jornais famosos, Rachel de Queiroz fica reduzida a sua atuação formal como "professora" e "jornalista". Além disso, Rachel de Queiroz é mencionada por se envolver em polêmicas por causa da publicação do romance $O$ quinze, questão que causa um impacto no leitor. Enquanto Cecília é apresentada apenas através de seu principal poema e não são mencionados impactos/discussões sobre a sua obra.

Já no livro B, a relação estabelecida entre as autoras modernistas, apresenta algumas diferen-

https://periodicos.unifap.br/index.php/letras

Macapá, v. 10, n. 1, $1^{\circ}$ sem., 2020 
ças. Ao representar Rachel de Queiroz através de sua função social como "escritora" e "romancista", o texto ressalta o trabalho desenvolvido por Rachel de Queiroz no movimento literário, perspectiva que difere do livro A, que apenas aponta a função social de "professora" e "jornalista" para a escritora. Já Cecília Meireles é primeiramente colocada como professora, tal informação pode conduzir a produção de significado para a ideia de

que a escritora tem como função principal o ensino. Isso é reforçado mais adiante quando é colocada como "educadora". Tais perspectivas podem nos encaminhar para o entendimento de Cecília Meireles como uma imagem feminina relacionada à sensibilidade.

No livro C, o box com informações biográficas de Cecília Meireles contém pouquíssimos aspectos de sua vida, não são mencionadas informações pessoais e políticas sobre os ideais da poetisa. Entretanto, quando as informações biográficas de Rachel de Queiroz são apresentadas, quase todas referentes a perspectivas políticas da autora. Ambas não são mencionadas pelo seu papel social exercido no movimento modernista no texto, exceto no fim da seção sobre Rachel de Queiroz ao tratá-la como romancista. Cecília Meireles tem a sua temática amplamente abordada tanto no box biográfico quanto na parte referente à sua obra, apesar da omissão sobre a criação mais famosa da autora, Romanceiro da Inconfidência, não ser mencionada. Informação que poderia ser colocada em oposição às informações apresentadas sobre Cecília Meireles, visto que a temática apresentada sobre sua obra não perpassa por problemas sociais e políticos. Já a temática abordada sobre Rachel de Queiroz é mais caracterizada pelas perspectivas políticas/sociais que a principal temática de sua obra, a seca.

\section{Considerações finais}

Ao resgatarmos o contexto histórico do início do século XX, percebemos que muitas dessas questões ainda são atuais, como a desvalorização das escritoras mulheres e a propagação de um ideal de mulher, ainda muito ligado ao considerado como "feminino" (cuidar da casa, ser mãe, ser sensível). Pensando na propagação desses discursos até os dias de hoje é que objetivamos investigar como as autoras Rachel de Queiroz e Cecília Meireles, pertencentes à geração de 30 do modernismo, foram representadas nos livros didáticos de Ensino Médio aqui escolhidos.

A ACD, dessa forma, se tornou uma escolha teórica pertinente, pois busca abordar questões sociais para apontar as relações de poder que se materializam nos discursos e são perpetuadas por eles. Assim, dois conceitos foram de grande valia: o de discurso, pois Fairclough $(2016,2003)$ afirma que o discurso é uma forma de representação; e o de contexto, já que ele atua como regular do discurso.

A partir dessa noção do discurso enquanto representação social é que aliamos a ACD à Teoria das Representações Sociais proposta por van Leeuwen (2008), sendo esta teoria a escolha metodológica para analisarmos como as autoras modernistas são representadas. Dessa teoria, utilizamos as categorias de functionalization e rough polítical alignment. Tais percepções nos auxiliaram a compreender que as autoras modernistas Rachel de Queiroz e Cecília Meireles são significadas na produção discursiva pelas funções exercidas no movimento modernista e por seus posicionamentos políticos, respectivamente.

Assim, a partir das análises, pudemos observar que Rachel de Queiroz é representada nas obras, com exceção do livro A, exclusivamente como uma autora ligada ao tema da seca, embora os escritos da autora abordem outros aspectos, como a análise psicológica dos personagens, o coronelismo, a religiosidade. Além disso, as funções sociais de cronista, dramaturga, romancista de Rachel de Queiroz não são destacadas como as de Cecília Meireles. Na biografia introdutória da autora, sempre se destacam dois aspectos: a fuga da seca ainda cedo e o fato de ser a primeira escritora mulher da Academia Brasileira de Letras, informações presentes em todos os livros analisados, exceto no livro C. Sobre essa fuga da seca, interessante observar como esse contexto serve para antecipar, para o leitor, o discurso de denúncia da miséria causada pela seca.

Já em relação à Cecília Meireles, o que aparece de forma mais proeminente a respeito da

https://periodicos.unifap.br/index.php/letras

Macapá, v. 10, n. 1, $1^{\circ}$ sem., 2020 
figura dela está ligada ao delicado, ao sensível, ao feminino, à intuição. Há uma grande valoração sentimental atrelada à sua imagem e, no geral, podemos afirmar que os(as) autores(as) possuem uma visão mais prototípica dela do que Rachel de Queiroz. Isso ocorre porque a poeta nos remete à imagem de uma mulher "bem vista" pela sociedade. Como afirmam Maluf e Mott (1998, p.190): “O perfil traçado para a esposa conveniente contava ainda com indefiníveis qualidades, tais como simplicidade, justiça, modéstia e humor”. Embora as autoras estejam se referindo principalmente às primeiras três décadas do século XX, sabemos que esse discurso reverbera até os dias atuais, inclusive na maneira de representar Cecília Meireles, que é uma autora que possui mais espaço do que a própria Rachel de Queiroz, principalmente por ser constantemente ligada a esse lado sensível - e até maternal.

Assim, as análises reforçam a importância do contexto, atuando como norteador dos discursos sobre as autoras, fazendo com que o leitor foque em alguns sentidos propostos, e não sobre outros. Isso repercute na proeminência de elementos que elevam a condição de uma autora que escreveu não apenas sobre a temática da seca, mas da própria mulher inserida nesse cenário de miséria, de luta contra o patriarcado com fortes perspectivas ideológicas. Isso não ocorre em todos os livros. Muitas vezes, Rachel de Queiroz sequer é mencionada por suas funções sociais, ou quando é representada, recebe pouco destaque. Mesmo que tenha sido representada como uma das precursoras do romance social de 30, a escritora se enquadra bem na definição da figura ameaçadora ao perfil da esposa conveniente: "[...] a moça dos tempos modernos, 'esbagachada', cheia de liberdades [...]” (MALUF; MOTT, 1998, p.1990).

Por outro lado, Cecília Meireles é a mulher ideal. Sensível, feminina, delicada, materna, intuitiva. Esses são os principais elementos destacados para compreendermos a figura da autora e como isso repercute em sua obra, explicando por que ela tem mais espaço do que Rachel de Queiroz, pois reforça o estereótipo de como a mulher deve ser.

Portanto, pensando o discurso a partir do proposto por Fairclough (2016) enquanto uma forma de ação, capaz de significar e (re)construir o mundo, defendemos que a maneira como essas autoras foram representadas nos livros didáticos realiza uma manutenção do discurso reprodutor de estereótipos sobre o comportamento feminino, mantendo o status quo; porém, novas representações sociais podem ser construídas, e defendemos o próprio livro didático, e o papel do professor no processo de aprendizagem do estudante, como parte essencial desse processo discursivo de mudança.

\section{REFERÊNCIAS}

CEREJA, W.; DIAS VIANNA, C.; DAMIEN, C. Capítulo 1: A geração de 30 - Graciliano Ramos. In: _. Português contemporâneo: diálogo, reflexão e uso, volume 3. 1ed. São Paulo: Saraiva, 2016, p.100-113.

CEREJA, W.; DIAS VIANNA, C.; DAMIEN, C. Capítulo 1: A poesia de 30 - Cecília Meireles e Vinicius de Morais .In:__. Português contemporâneo: diálogo, reflexão e uso, volume 3. 1ed. São Paulo: Saraiva, 2016, p.182-189.

FAIRCLOUGH, N. Discurso e mudança social. 2ed. Brasília: Editora Universidade de Brasília, 2016. FAIRCLOUGH, N. Analysing discourse: textual analysis for social research. London: Routledge, 2003.

HERNANDES, R; MARTIN, V. L. Capítulo 10: segunda geração modernista - o romance social de 1930. In: __ Veredas da palavra: volume 3. 1 ed. São Paulo: Editora Ática, 2016, p.188-192. HERNANDES, R; MARTIN, V. L. Capítulo 9: segunda geração modernista - a poesia de 1930. In: . Veredas da palavra: volume 3. 1 ed. São Paulo: Editora Ática, 2016, p.167-185.

HOLANDA, A. Questões sobre pesquisas qualitativa e fenomenológica. Análise psicológica, Lisboa; v. 24, n. 3, p. 363-372, 2006.

JAFFE, N. Posfácio. In: Woolf, V. Um teto todo seu. São Paulo: Tordesilhas, 2014.

MAGALHÃES, I; MARTINS, A. R.; RESENDE, V. M. Análise de discurso crítica: um método de

https://periodicos.unifap.br/index.php/letras

Macapá, v. 10, n. 1, $1^{\circ}$ sem., 2020 
pesquisa qualitativa. Brasília: Editora Universidade de Brasília, 2017.

MALUF, M.; MOT'T, M. L. Recônditos do mundo feminino. IN: NOVAIS, Fernando. A.; SEVENCKO, Nicolau (Orgs.). História da vida privada no Brasil: república: da belle époque à era do rádio. vol.3. São Paulo: Companhia das Letras, 1998.

NICOLÁ, J. de. O Brasil de 1930 a 1945 - a lírica. In: de texto: volume 3. São Paulo: Editora Scipione, 2012, p.244-268.

NICOLÁ, J. de. O Brasil de 1930 a 1945 - o romance. In: texto: volume 3. São Paulo: Editora Scipione, 2012, p.269-297.

RAGO, L. M. Cultura feminina e tradição literária no Brasil, 1900-1932. In: SWAIN, Tânia; GOTIJO, Diva (Orgs.). Mulheres em ação. Práticas discursivas, práticas políticas. 1ed. Florianópolis: Editora das Mulheres, 2005.

RAMALHO, V; RESENDE, V. Análise de discurso (para a) crítica: o texto como material de pesquisa. Campinas: Pontes, 2011.

REISIGL, M; WODAK, R. Discourse and discrimination: rhetorics of racism and antisemitism. Londres: Routledge, 2001.

VAN DIJK, T. A. Discurso y poder. Barcelona: Editora Gedisa, 2009.

VAN LEEUWEN, T. Discourse and practice: new tools for critical discourse analysis. Nova York: Oxford University Press, 2008.

WOOLF, V. Um teto todo seu. São Paulo: Tordesilhas, 2014. 